\title{
Sebaceous carcinoma of the eyelid: a clinicopathological study
}

\author{
Marlis Zürcher, Christoph R Hintschich, Alec Garner, Catey Bunce, J Richard O Collin
}

\begin{abstract}
Background-Sebaceous carcinoma of the eyelid is rare. The diagnosis might be difficult because of its ability to masquerade as other periocular lesions. Prognosis is still regarded as being poor compared with most other malignant eyelid tumours with a mortality second only to malignant melanoma. The present study retrospectively analyses clinical and histopathological findings and outcome in a series of patients with sebaceous carcinoma of the eyelid in Britain.
\end{abstract}

Methods-43 patients with histologically confirmed sebaceous carcinoma treated at Moorfields Eye Hospital between 1976 and 1992 were subjected to retrospective analysis. Clinical data of all patients were reviewed from the charts; all surviving patients except four cases lost for follow up were re-examined. Histological specimens were reviewed in 41 cases.

Results-23 females and 20 males, mean age 63 years (range 37-79), were treated. Primary therapy was surgery in 37 and radiotherapy in six cases. After a median follow up of 40 months (range 1-148) 30 patients were alive without recurrences, four patients had died from the tumour, and one was alive with local recurrence and distant metastases. Four patients had died of non-tumour related causes. Histologically, unfavourable outcome was correlated with poor tumour differentiation and extensive invasion.

Conclusion-Early diagnosis and consequent surgical therapy of sebaceous carcinoma of the eyelid leads to a better outcome and higher survival rates than generally assumed. Even local recurrences can be treated successfully. However, sebaceous carcinoma remains a threatening disease, which leads to death in $9 \%$ and to mutilating exenteration in $23 \%$ of our patients.

(Br f Ophthalmol 1998;82:1049-1055)

Moorfields Eye

A Garner

J R O Collin

Glaxo Department of Ophthalmic

Epidemiology,

Moorfields Eye

Hospital, London

C Bunce

Correspondence to:

Mr J R O Collin, Moorfields

Eye Hospital, City Road,

London EC1V 2PD.

Accepted for publication 24 March 1998

Sebaceous carcinoma of the eyelid may arise from the diverse sebaceous glands of the ocular adnexa. ${ }^{1}$ Owing to its rarity and its ability to masquerade as other periocular lesions, diagnosis of the disease might be difficult. ${ }^{1-9}$ Prognosis is still regarded as being poor compared with most other malignant eyelid tumours with a mortality second only to malignant melanoma. ${ }^{1}{ }^{10-13}$ Comprehensive studies, however, are few and there is a substantial difference between surveys from America, where the tumour is rare with an incidence ranging from $0.2 \%$ to $4.7 \%$ of malignant epithelial eyelid tumours, ${ }^{1}{ }^{10} 11$ and China, where the tumour is reported to occur in $28 \%$ of the lid cancers. ${ }^{12}$ The purpose of our study was to analyse the natural history of the tumour and its response to treatment in a series of patients in Britain.

\section{Patients and methods}

From 1976 to 1992,43 patients with histologically confirmed sebaceous carcinoma were treated at Moorfields Eye Hospital in London. Data on patients' history, clinical features, therapy, and outcome were collected retrospectively. In addition, all surviving patients except four, who were lost to follow up, were re-examined clinically. In 41 cases the histological specimens were reviewed and assessed. Histological evaluation was based on the study of conventional paraffin embedded sections supplemented in most cases by oil red $\mathrm{O}$ stained frozen sections.

The binomial method was used to assess evidence that sebaceous carcinoma is more likely to occur in left versus right eye or upper versus lower lid. We did not conduct any multivariate analyses when studying survival time and time to recurrence, bearing in mind that the power of such tests relates to the number of events not to the number of subjects. ${ }^{14}$

\section{Results}

Characteristics of our study population are presented in Table 1, patient details including sex, race, age at diagnosis, tumour position and size, time between first presentation and treatment, modalities of therapy, complications, and outcome are shown in Table 2.

\section{PATIENTS' HISTORY}

Twenty three women and 20 men were treated. Patients' age at time of correct diagnosis ranged from 38 to 79 years (mean age 62.6 years). Forty two patients were white with two Indian, one Arab, one Maltese, and one Spanish patient, and one patient was Asian from China. The Asian, Maltese, and Spanish patients had lived in their countries of birth for at least 10 years.

Details of the medical history were obtained in 33 patients. One patient had received radiotherapy for facial acne (dose unknown), one had a history of multiple basal cell carcinomas on his back, and one had been treated surgically for an osteosarcoma of the femur 25 years earlier. No patient had been exposed to chemotherapy for any reason before manifestation of the sebaceous carcinoma.

Thirteen of 29 patients interviewed gave a positive family history of cancer with four of them having more than one affected relative. 
Table 1 Characteristics of study population

\begin{tabular}{lll}
\hline Study factor & No & $\%$ \\
\hline Sex & & \\
$\quad$ Male & 20 & 47 \\
$\quad$ Female & 23 & 53 \\
Race & & \\
$\quad$ White & 42 & 98 \\
$\quad$ Chinese & 1 & 2 \\
Size of tumour (mm) & & \\
5-10 & 11 & 27.5 \\
11-20 & 13 & 32.5 \\
$21-30$ & 6 & 15 \\
$\quad$ Diffuse & 10 & 25 \\
Eye affected & 27 & 63 \\
$\quad$ Left & 16 & 37 \\
Right & 29 & 67 \\
Tumour on upper lid & 17 & 40 \\
Tumour on lower lid & 14 & 33 \\
Tumour on conj/cornea & 2 & 5 \\
Tumour in orbit & 1 & 2 \\
Diffuse tumour & & \\
Age (years) & & \\
$\quad$ Median & Range \\
Follow up time (months) & $37-79$ \\
$\quad$ Median & & \\
Range & 40 & \\
\hline
\end{tabular}

The tumours included four cases of gastric carcinoma, two of breast carcinoma, and one each of cancer of the skin, brain, lung, prostate, throat, and liver.

\section{CLINICAL FEATURES}

Twenty seven of the carcinomas were found on the left, 16 on the right side $(p=0.12$; binominal test). The tumour was localised in the upper eyelid in 26 patients, and less frequently in the lower eyelid in 14 patients $(p=0.08)$. Both lids were involved in three cases. The conjunctiva was affected in 14 patients, three of them additionally had corneal epithelial changes. At the time of diagnosis two patients showed intraorbital tumour, two had local lymph node metastases, and one had a distant metastasis.

Tumours were graded as small $(<10 \mathrm{~mm})$ in 11 cases, of medium size $(10-20 \mathrm{~mm})$ in 14 cases, and large $(>20 \mathrm{~mm})$ in six cases. In 10 patients, the tumour was diffuse or multifocal, imitating a blepharoconjunctivitis, and could not be measured accurately. In two cases no measurements were available.

The diagnoses were made on histological examinations based on specimens obtained by incisional biopsy in 14 cases (one combined with conjunctival biopsy), full thickness eyelid biopsies in 23 cases (mainly excisional biopsies), and three excisional biopsies which were not further specified. A conjunctival biopsy only was performed in two eyes. In one patient the diagnosis was made from the exenteration specimen.

At the time of referral a correct initial diagnosis had been established in only eight of 43 patients $(18.6 \%)$. The most frequent clinical misdiagnosis was chalazion (19 patients) (Fig 1), followed by chronic blepharoconjunctivitis (eight patients) (Fig 2), basal cell carcinoma (four patients) (Fig 3), epithelial carcinoma in situ (four patients), and squamous cell carcinoma (three patients). Other isolated misdiagnoses at presentation included leucoplakia, sweat gland carcinoma, and papilloma. More than one misdiagnosis during the course of the disease until the definite histological diagnosis was made was found in five patients.

The time interval between first documented symptoms and diagnosis ranged from 1 month to 15 years (median 12 months). Only 13 patients $(30 \%)$ were diagnosed within 6 months of the first symptoms. After the definitive diagnosis had been established, therapy was instituted at a median time of 1 month.

The follow up beginning after the first treatment at Moorfield's ranged from 1 month to 12.3 years (median 3.3 years). Four patients were lost to follow up after 1, 2, 60, and 87 months, respectively.

\section{THERAPY}

The primary treatment at Moorfields Eye Hospital was mainly a surgical approach. Thirty seven patients were operated on, and only six were treated by radiotherapy. Surgery consisted of extensive excision with a macroscopically tumour free margin of at least $4 \mathrm{~mm}$. The surgical margin was evaluated histologically by frozen section in 10 patients and by Mohs' technique in one patient. Primary orbital exenteration had to be performed in eight patients.

\section{OUTCOME}

At the end of the survey 30 patients were alive without detectable tumour recurrences. One patient was alive but had a local recurrence and distant metastases. Eight patients had died during the period of follow up. In four there was a tumour related cause. One patient died from metastatic disease of her eyelid tumour (no 29), and three from causes related to their lid carcinoma, but which were not proved by necropsy (patient nos 19,31, and 41). In the other four cases death was due to bronchogenic carcinoma in two and to unknown causes in the other two. All four patients who died from sebaceous carcinoma had received palliative radiotherapy as primary treatment. The two patients dying from unknown causes had undergone orbital exenteration. None of the patients treated surgically died from tumour related causes.

Four patients were lost to follow up-two immediately after the treatment, one after 5 years, and another after 7 years of recurrencefree follow up.

Twelve patients $(28 \%)$ suffered from either local recurrences and/or distant metastases. Six (14\%) of them developed only a local tumour recurrence after 2 to 48 months (median 9 months). Preauricular lymph node metastases were seen in six patients 6-24 months (median 14 months) after initial treatment. Three patients showed both local recurrence and preauricular lymph node involvement. One of these patients (no 26) developed histologically confirmed distant subcutaneous metastases as well.

Local tumour recurrences were managed by repeated local excision in six and orbital exenteration in two patients. Preauricular lymph node metastases were treated by radical neck dissection, usually combined with partial 


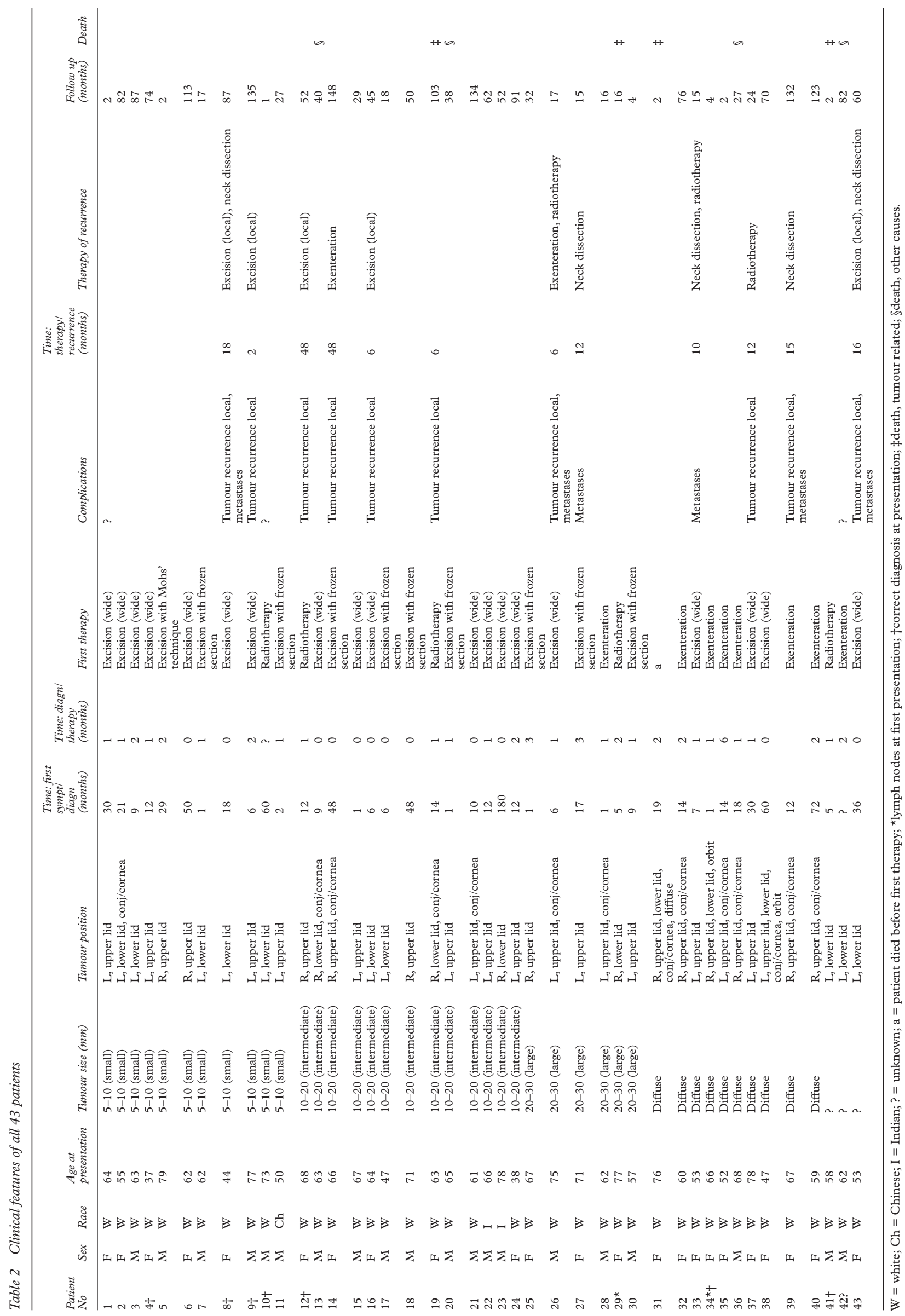

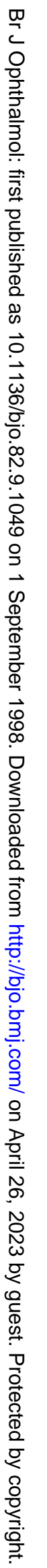



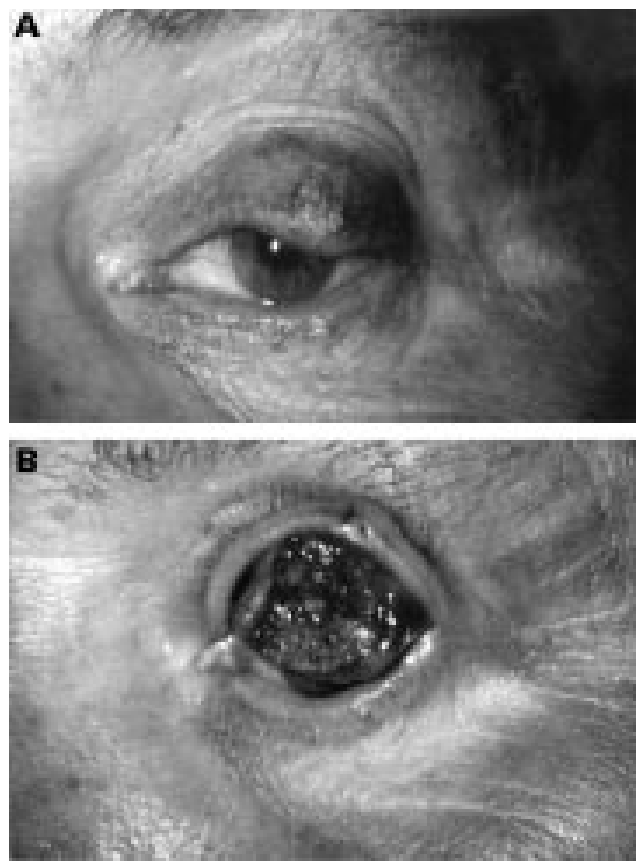

Figure 1 (A) Sebaceous carcinoma of the left upper lid presenting as a firm, nodular, and non-tender mass. (B) Same lid everted with the lesion originating from the tarsal plate.

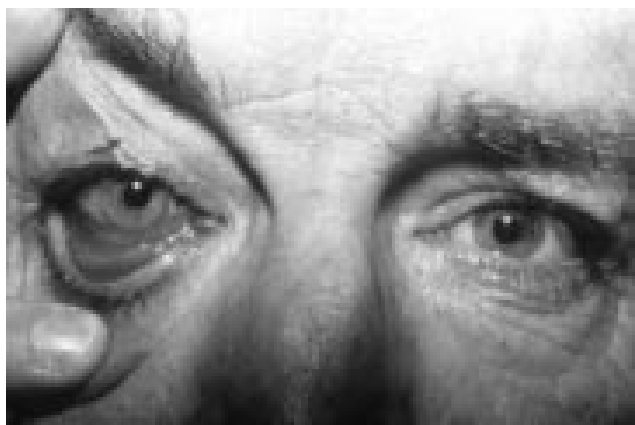

Figure 2 Sebaceous carcinoma presenting as a chronic blepharoconjunctivitis in the right eye.

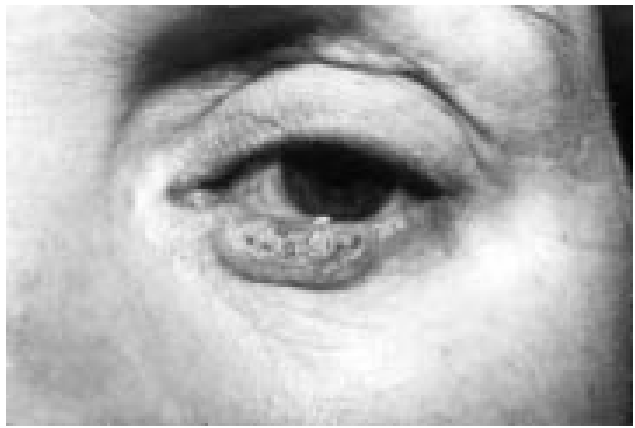

Figure 3 Sebaceous carcinoma presenting as a basal cell carcinoma of the left lower lid.

parotidectomy. In one case, local recurrence with lymph node metastasis was treated by excision and radiotherapy of the face and neck.

A subjective assessment of the functional and cosmetic outcome was carried out in 27 patients excluding the patients subjected to orbital exenteration. The functional result was regarded as good in 19, moderate in six, and poor in two patients, whereas the cosmetic outcome was regarded as good in 23 , moderate in three, and poor in one patient.
HISTOPATHOLOGY

A review of the histopathological specimens was possible in 41 of 43 cases. The features which were evaluated include pattern, differentiation, stromal invasion, epithelial involvement, and mitotic activity.

\section{Pattern}

A lobular arrangement of cells was apparent in 36 cases (Fig 4). One tumour had a predominantly papillary pattern and four were mixed. There was no example of a pure form of comedo carcinoma.

\section{Differentiation}

On the basis of the proportion of tumour cells which had abundant vacuolated or foamy cytoplasm and were comparable in appearance to normal sebaceous tissue, individual lesions were categorised as well differentiated in 12 cases (Fig 4), moderately differentiated in 22 and poorly differentiated in seven cases (Fig 5).

\section{Invasion}

Tumours which showed generally circumscribed lobules and little evidence of stromal infiltration accounted for nine cases (Fig 4). A moderate stromal invasion but with preservation of the lobular structure was observed in 21 specimens. In the remaining 11 cases a more extensive infiltration with a break up of the lobules was observed (Fig 5).

\section{Epithelial involvement}

Pagetoid spread within the adjacent surface epithelium was observed in 16 cases in the form of isolated or, more commonly, groups of tumour cells infiltrating and replacing the basal layers (Fig 6). In some instances, where the infiltration was extensive, this was associated with degeneration and acantholysis of the overlying epidermis and/or conjunctival epithelium. In 11 cases there was full thickness replacement of the surface epithelium by tumour tissue (Fig 7) in the absence of ulceration resembling epithelial carcinoma in situ (Bowen's disease). In one case areas of both pagetoid and carcinoma in situ changes were visible. In the remaining 14 cases there was no apparent involvement of the surface epithelium.

\section{Mitotic activity}

Semiquantitative assessments based on the number of mitotic figures identified per high power microscopic field $(\times 250)$ gave a range of 1-12 and a mean of 5.8 .

\section{Discussion}

Although carcinoma of the meibomian glands was described more than a century ago by Fuchs, ${ }^{15}$ subsequent reports have been infrequent and usually limited to single cases. In 1956, Straatsma ${ }^{16}$ published the first extensive series, which did much to clarify the natural history and the prognosis of sebaceous carcinoma of the eyelid. Since then several other studies have appeared. ${ }^{17121718}$ Comprehensive reviews are available. ${ }^{19} 20$ 


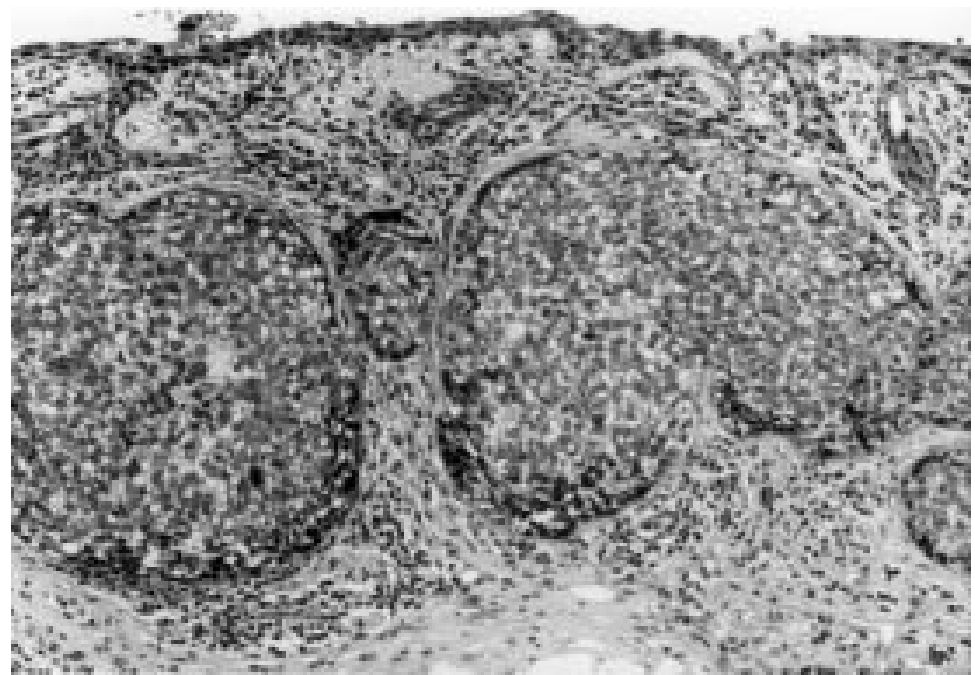

Figure 4 Well differentiated lobular sebaceous carcinoma with minimal stromal infiltration (original magnification $\times 190$ ).

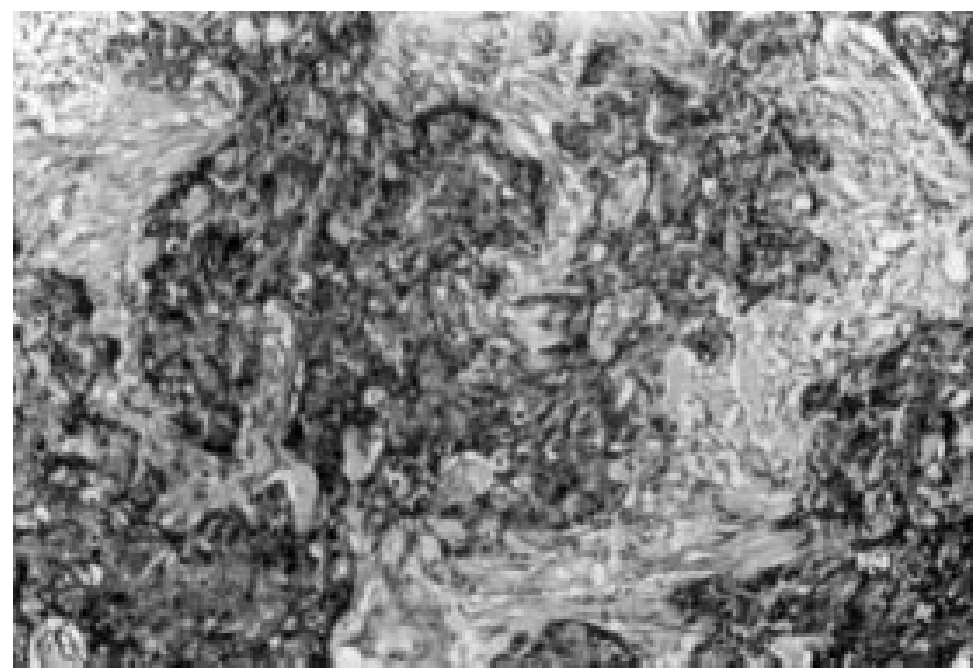

Figure 5 Poorly differentiated sebaceous carcinoma with extensive stromal infiltration (original magnification $\times 190$ ).

Sebaceous carcinoma is an uncommon skin tumour which accounts for less than $1 \%$ of malignancies of the skin. ${ }^{21}$ It occurs most frequently on the eyelids, where it comprises $4.7 \%$ of malignant epithelial tumours. ${ }^{10}$ The incidence on the eyelid is subject to considerable geographical variation. Among white people the tumour is rare and, according to reports from the USA, represents between $0.2 \%$ and $1.2 \%$ of all lid lesions and between $1.13 \%$ and $3.2 \%$ of all malignant lid neoplasms. ${ }^{22-24}$ In China and other Asian countries forming the western Pacific seaboard, the incidence appears to be much higher; one study from Shanghai gave an incidence of $32.7 \%$ of all eyelid malignancies. ${ }^{25}$ Since in our study there was only one Asian patient, who had lived for at least 10 years in the country of birth, we cannot give a statement concerning the possible influence of racial factors in the propensity to develop sebaceous carcinoma.

In the literature a higher incidence for females is suggested with a female to male ratio of 1.51 to $1.0 .^{1013162426-30}$ In our study as in

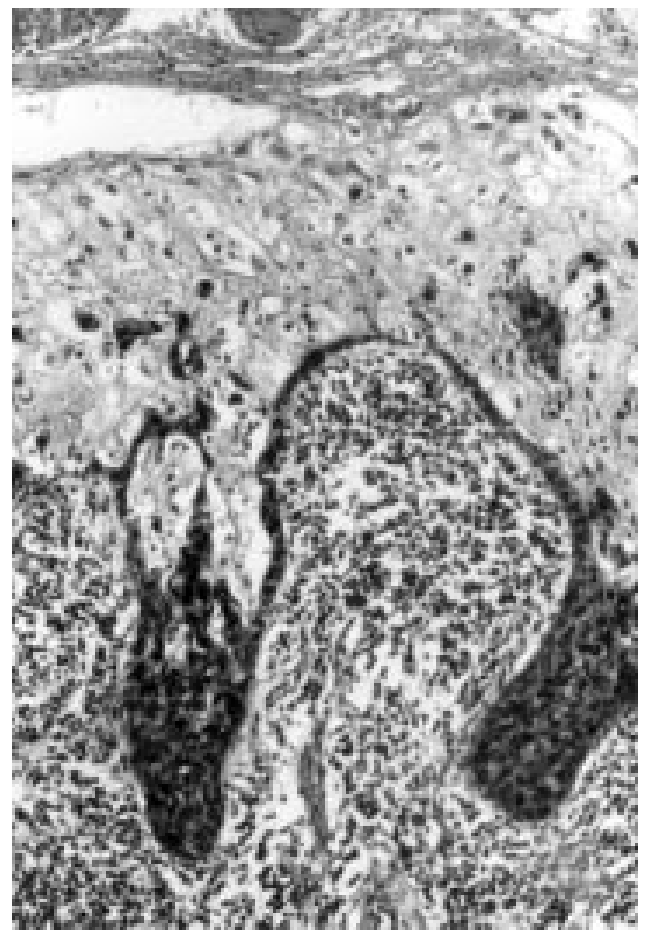

Figure 6 Sebaceous carcinoma with pagetoid spread in the form of groups of tumour cells infiltrating and replacing the basal layers of the epithelium (original magnification $\times 190)$.

some others, ${ }^{18} 26$ there was no significant sex distinction.

The median age of our patients at diagnosis was 63 years, which is similar to other studies (means between 57 and 68 years). ${ }^{1}{ }^{12} 16172628$ Sebaceous carcinoma of the eyelid in younger patients is apparently a rare event and, not infrequently, appears to be associated with prior radiotherapy. ${ }^{31-33}$ Neither of the two patients in our series aged under 40 had been exposed in this way.

The tumour originates in the upper lid more often than in the lower lid. The ratio varies from 1.3 to 3.0 in the published series. ${ }^{12} 161728$ In our series, the ratio of upper to lower lid was 1.8 (including three cases with involvement of both lids). These data provide some evidence $(p=0.08)$; predominance of the upper eyelid possibly reflects the greater number of meibomian glands in the upper eyelid. ${ }^{10-13} 17283435$

The clinical diagnosis of sebaceous carcinoma may be difficult, partly because it is rarely encountered and partly because of its propensity to simulate other eyelid lesions. ${ }^{2} 836$ We have reported on this aspect previously. ${ }^{8}$ The present paper emphasises this difficulty. Chalazion, followed by blepharoconjunctivitis, was the most common misdiagnosis, with other benign and malignant neoplasms also causing significant problems. In exceptional patients the presenting sign is enlarged cervical lymph nodes, the usual primary lid lesion being inconspicuous and easily overlooked..$^{1-7} 9$ Two of our patients presented with preauricular lymph node metastases at the time of diagnosis.

These diagnostic difficulties must be accepted and emphasise the importance of biopsies in uncertain and suspicious inflammatory 


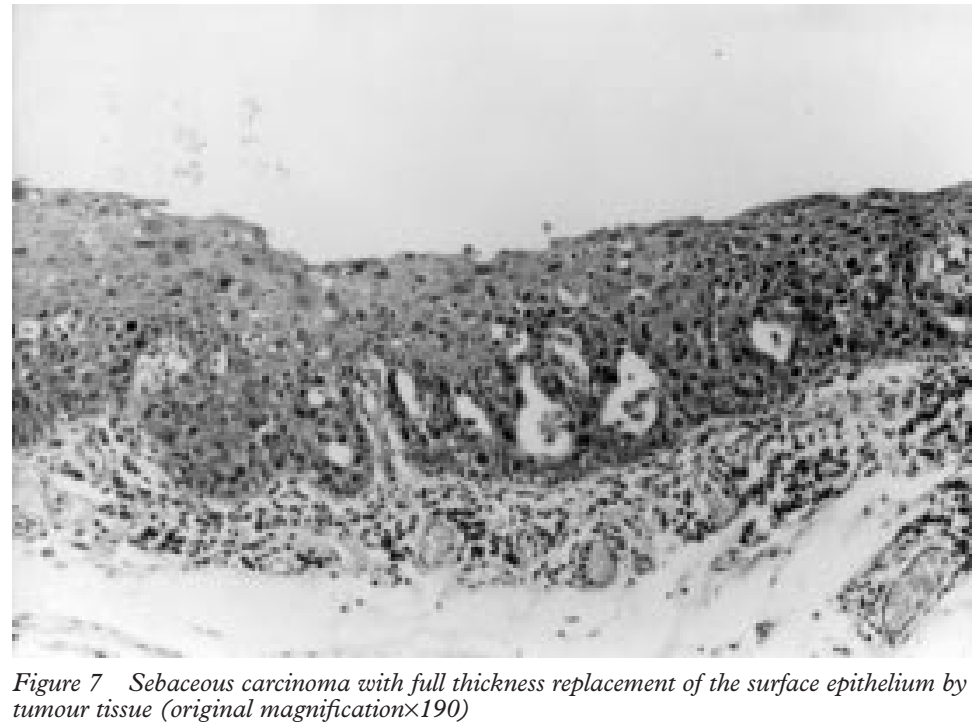

states which fail to respond to appropriate treatment. ${ }^{4738}$ A full thickness eyelid biopsy, combined with conjunctival biopsies in certain cases, is the appropriate approach. The importance of histological examination of all suspicious chalazia must also be stressed. This is not to claim that histopathological diagnosis is always straightforward: in one of our patients, presenting as an ostensible case of blepharoconjunctivitis, the presence of minor pagetoid spread in a biopsy specimen was initially overlooked contributing to a delay in diagnosis from the first symptoms of 60 months. Nevertheless, after review of the histological specimens the diagnoses on all biopsies taken at Moorfields Eye Hospital proved to be correct.

It might be anticipated that the sooner appropriate treatment is instituted the better the prognosis and a number of published reports bear this out, ${ }^{11} 131639$ although our own data are inconclusive.

Numerous factors have been reported to influence the prognosis. Because of the small number of tumour deaths in our series one cannot really comment much on this. However, tumours in excess of $10 \mathrm{~mm}$ are associated with a particularly poor outcome ${ }^{17}$; the patients in our current report with tumour related deaths fell into this group. Tumours of the upper lid have been associated with an adverse outcome relative to those affecting the lower lid. ${ }^{13}$ Conversely, our own data suggest that lesions in the lower lids may do worst. Three of the patients who died of tumour related causes presented with a lower lid carcinoma, the fourth with an upper and lower lid tumour (Table 1). A larger size of the tumour cannot be an explanation, as the mean size of the upper lid lesions at the time of presentation was $15.7 \mathrm{~mm}$, the size of lower lid tumours only $12.8 \mathrm{~mm}$. Carcinomas of the gland of Zeis are claimed to have the best prognosis. ${ }^{13} 17$ While our own experience does not run contrary to these conclusions, the numbers of tumours that could accurately be linked to a definite origin (glands of Zeis, meibomian glands, or caruncle) do not justify a firm statement. Histopathological features such as tumour differentiation, extent of infiltration, and intraepithelial spread have also been linked to prognosis. $^{713}$ Our own findings, while numerically insufficient to be conclusive, tend to support these conclusions (Table 3). Comment on the risk of local recurrence based on histological evaluation of the excised tumour is similarly restricted by the small numbers involved. Thus, while there was a tendency for well differentiated tumours to fare best and for those lesions with marked stromal infiltration and epithelial involvement to run greater risk, the differences were insufficient to permit an accurate prognosis in individual cases (Table 3).

Adequate therapy requires wide excision of the lesion with a tumour free margin of at least $4 \mathrm{~mm}$. Frozen section control and Mohs' technique should only be employed in specialised centres with experienced ophthalmic pathologists, as these methods may alter the histological appearance of sebaceous carcinoma. ${ }^{40}$ Correct therapy in patients with multifocal tumours and extensive pagetoid spread through the conjunctiva is exenteration. The considerable number of 10 patients out of 43 have suffered such radical therapy, cases of the recurrences included. With one exception, all patients in our series initially treated by palliative radiotherapy subsequently died.

Sebaceous carcinoma is reported to recur in $6 \%$ to $29 \%$ of cases. ${ }^{71-1326}{ }^{27}$ In our series local recurrence in the lids was seen in $14 \%$ of the patients, while orbital extension was observed in $5 \%$. According to the literature, distant metastasis affects $14-25 \%$ of cases and involves lymph node or haematogenous spread into liver, lungs, brain, and bones. ${ }^{19} 10131742$ The majority of all recurrences appear within the first 4 years after treatment. ${ }^{16}$ Our median time to recurrence was 12 months (2-48 months). Only one of our patients who underwent exenteration developed a recurrence (lymph node metastasis). All five patients in our series with local lymph node metastases were cured by radical neck dissection in combination with partial parotidectomy. None

\begin{tabular}{|c|c|c|c|c|c|c|}
\hline & \multicolumn{6}{|c|}{ Histological features } \\
\hline & \multicolumn{3}{|c|}{ Differentiation } & \multicolumn{3}{|l|}{ Invasion } \\
\hline & Well & Moderate & Poor & Slight & Moderate & Extensive \\
\hline All cases $(n=41)$ & 12 & 22 & 7 & 9 & 21 & 11 \\
\hline Cases of recurrence or metastasis $(\mathrm{n}=10)$ & $2(16.7 \%)$ & $6(27.3 \%)$ & $2(28.6 \%)$ & $2(22.2 \%)$ & $3(14.3 \%)$ & $5(45.4 \%)$ \\
\hline Cases of tumour related death $(n=4)$ & $00 \%$ & $2(9.1 \%)$ & $2(28.6 \%)$ & $00 \%$ & $1(4.8 \%)$ & $3(27.3 \%)$ \\
\hline
\end{tabular}


of them suffered a further recurrence after a median follow up of 28 months ( 3 months to 9 years).

Tumour related deaths were seen in four patients $(9.3 \%)$. All of these patients in our study have been treated with palliative radiotherapy in the absence of surgery. So far, all patients treated surgically have survived. However, 10 of them suffered exenteration procedure.

Patients must be followed up at short intervals postoperatively as the tumour has a fast growth potential. Adequate follow up includes meticulous inspection of the local site. Palpation of the preauricular, submandibular, and neck lymph nodes is mandatory. Currently, we see all patients 1 month postoperatively and at 3 monthly intervals during the first year, at 6 monthly intervals during the second year, and then on a yearly basis for life. These are approximate guidelines.

This paper was presented in part at the Royal College of Ophthalmologists Meeting 1994 in Guernsey, UK

This study was supported by the Verrey-Foundation, Lausanne, Switzerland.

1 Boniuk M, Zimmerman LE. Sebaceous carcinoma of the eyelid, eyebrow, caruncle, and orbit. Trans Am Acad eyelid, eyebrow, caruncle, and orbit.

2 Brownstein S, Codere F, Jackson WB. 1. Masquerade syndrome. Ophthalmology 1980;87:259-62.

3 Condon GP, Brownstein S, Codere F. Sebaceous carcinoma of the eyelid masquerading as superior limbic keratoconjunctivitis. Arch Ophthalmol 1985;103:1525-9.

4 Russel WG, Page DL, Hough AJ, et al. Sebaceous carcinoma of meibomian gland origin. The diagnostic importance of pagetoid spread of neoplastic cells. Am f Clin Pathol 1980;73:504-11

5 Shields JA, Font RL. Meibomian gland carcinoma presenting as a lacrimal gland tumor. Arch Ophthalmol 1974;92: 304-6.

6 Wagoner MD, Beyer CK, Gonder JR, et al. Common presentations of sebaceous gland carcinoma of the eyelid. Ann Ophthalmol 1982;14:159-63.

7 Wolfe JT, Yeatts RP, Wick MR, et al. Sebaceous carcinoma of the eyelid. Errors in clinical and pathologic diagnosis. of the eyelid. Errors in clinical

8 Wright P, Collin JRO, Garner A. The masquerade syndrome. Trans Ophthalmol Soc UK 1981;101:244-50.

9 Yeatts RP, Waller RR. Sebaceous carcinoma of the eyelid pitfalls in diagnosis. Ophthalmic Plast Reconstr Surg 1985;1: 35-42.

10 Doxanas MT, Green RW. Sebaceous gland carcinoma. Arch Ophthalmol 1984;102:245-9.

11 Ginsberg J. Present status of meibomian gland carcinoma Arch Ophthalmol 1965;73:271-7.

$12 \mathrm{Ni}$ C, Kuo PK. Meibomian gland carcinoma. A clinicopathological study of 156 cases with long-period follow-up of 100 cases. Fpn f Ophthalmol 1979;23:388-401.

13 Rao NA, McLean IW, Zimmerman LE. Sebaceous carcinoma of the eyelid and caruncle:correlation of clinicopathologic features with prognosis. In: Jakobiec FA. ed. Ocular and adnexal tumors. Birmingham, AL: Aesculapius, 1978:461-76.
14 Altman DG. Practical statistics for medical research. London: Chapman and Hall, 1991.

15 Fuchs E. Ueber das Chalazion und einige seltenere Lidgeschwülste. Von Graefe's Arch Ophthalmol 1878;24: $121-68$

16 Straatsma BR. Meibomian gland tumors. Arch Ophthalmol 1956;56:71-93

17 Rao NA, Hidayat AA. Sebaceous carcinoma of the ocular adnexa: a clinicopatholgic study of 104 cases, with five-year follow-up data. Hum Pathol 1982;13:13-122.

18 Pickford MA, Hogg FJ, Fallowfield ME, et al. Sebaceous carcinoma of the periorbital and extraorbital regions. $B r f$ Plast Surg 1995;48:93-6.

19 Khan JA, Doane JF, Grove AS Jr. Sebaceous and meibomian carcinomas of the eyelid. Recognition, diagnosis, and management. Ophthalmic Plast Recontr Surg 1991;7:61-6.

20 Nelson BR, Hamlet KR, Gillard M, et al. Sebaceous carcinoma. f Am Acad Dermatol 1995; 33:1-15.

21 Warren S, Warvi WN. Tumors of sebaceous glands. $A m \mathcal{F}$ Path 1943;19:441-59.

22 Aurora AL, Blodi FC. Lesions of the eyelids: a clinicopathological study. Surv Ophthalmol 1970;15:94-104.

23 Kwitko ML, Boniuk M, Zimmerman LE. Eyelid tumors with reference to lesions confused with squamous cell carcinoma. Arch Ophthalmol 1963;69:696-7.

24 Welch RB, Duke JR. Lesions of the lids: a statistical note. Am f Ophthalmol 1958;45:415-16.

$25 \mathrm{Ni}$ C, Searl SS, Kuo PK, et al. Sebaceous cell carcinoma of the ocular adnexa. In: Ni C, Albert DM, eds. Tumors of the the ocular adnexa. In: Ni C, Albert DM, eds. Tumors of the Int Ophthalmol Clin 1982;22:23-61.

26 Epstein GA, Putterman AM. Sebaceous adenocarcinoma of the eyelid. Ophthalmic Surg 1983;14:935-40.

27 Harvey JT, Anderson RL. The managment of meibomian gland carcinoma. Ophthalmic Surg 1982;13:56-61.

28 Sweebe EC, Cogan DG. Adenocarcinoma of the meibomian gland. Arch Ophthalmol 1959;61:282-90.

29 Luxenberg MN. Sebaceous gland carinoma. Arch Ophthalmol 1988; 106:119.

30 Tschornobay A, Levigne V, Favre J, et al. Extraocular sebaceous carcinoma. Acta Derm Venerol (Stockh) 1992; 72:20-1.

31 Bhalla JH, Vashisht S, Gupta VK, et al. Meibomian gland carcinoma in a 20-year-old patient (letter). Am $\mathcal{F}$ Ophthalmol 1991;111:114-15.

32 Lemos LB, Santa Cruz DJ, Baba N. Sebaceous carcinoma of the eyelid following radiation therapy. Am 7 Surg Pathol 1978;2:305-11.

33 Schlernitzauer DA, Font RL. Sebaceous gland carcinoma of the eyelid following radiation therapy for cavernous hemangioma of the face. Arch Ophthalmol 1976;94:152-5.

34 Callahan MA, Callahan A. Sebaceous carcinoma of the eyelids. In: Jakobiec FA, ed. Ocular and adnexal tumors. Birmingham, AL: Aesculapius, 1978:477-83.

35 Parsons JH. System of ophthalmology, the ocular adnexa. In. Duke-Elder S, ed. Diseases of the eyelids. 13th ed. New York: MacMillan, 1959:453-8.

36 Foster CD, Allansmith MR. Chronic unilateral blepharoconjunctivitis caused by sebaceous carcinoma. Am $\mathcal{F}$ Ophthalmol 1978;86:218-20.

37 Leibsohn J, Bullock J, Waller R. Full-thickness eyelid biopsy for presumed carcinoma in situ of the palpebral conjunctiva. Ophthalmic Surg 1982;13:840-2.

38 Putterman AM. Conjunctival map biopsy to determine pagetoid spread. Am $\mathcal{F}$ Ophthalmol 1986;102:87-90

39 Scheie HG, Yanoff M, Frayer WC. Carcinoma of sebaceous glands of the eyelid. Arch Ophthalmol 1964;72:800-3.

0 Folberg R, Whitaker DC, Nerad JA. Recurrent and residual sebaceous carcinoma after Mohs' excision of the primary lesion. Am f Ophthalmol 1987;103:817-23.

41 Tenzel RR, Stewart WB, Boynton JR, et al. Sebaceous adenocarcinoma of the eyelid. Definition of surgical margins. Arch Ophthalmol 1977;95:2203-4.

42 Pardo FS, Wang CC, Albert D, et al. Sebaceous carcinoma of the ocular adnexa: radiotherapeutic management. Int $\mathcal{F}$ Padiat Oncol Biol Phys 1989;17:643-7. 